\title{
ENSAIO SOBRE A CONSTRUÇÃO/DESCONSTRUÇÃO DA NOÇÃO DE SUJEITO NA CONTEMPORANEIDADE E A EDUCAÇÃ̃O/'DES-EDUCAÇÃO"
}

\author{
Marta Vanessa Oliveira de Souza
}

Professora na Escola Bahiana de Medicina e Saúde Pública. Mestrado em Psicologia.

Universidade Federal da Bahia.

\begin{abstract}
Resumo
A partir de uma frase proposta por J. Bronsky, escritor russo, em que cogita a "ameaça do novo", a autora mostra um retrato do sujeito na atualidade e como as noções e compreensões teóricas impactam no cotidiano da educação. O presente ensaio propõe uma reflexão sobre a educação atual, dialogando com o pensamento teórico contemporâneo da filosofia e sociologia. A partir de autores como o filósofo francês Jacques Derrida, com sua teoria sobre a dialética dos opostos, em que discute a desconstrução de conceitos; Jean Baudrillard, sociólogo que estuda os impactos da comunicação e das mídias na sociedade e na cultura contemporâneas; e Herbert Marcuse, sociólogo e filósofo alemão, pertencente à Escola de Frankfurt, que se preocupa com o desenvolvimento descontrolado da tecnologia e o racionalismo dominante nas sociedades modernas. O ensaio é finalizado com reflexões acerca da dificuldade de educar uma criança em meio a todos os problemas contemporâneos discutido pelos autores.
\end{abstract}

Palavras-chaves: Desconstrução; Educação; Contemporaneidade.

\begin{abstract}
From a sentence proposed by J. Bronsky, Russian writer, which is considering a "new threat", the author shows a picture of the subject at the present and how the concepts and theoretical understandings impact in everyday education. This paper proposes a reflection on the current education, dialogue with the contemporary theoretical thinking of philosophy and sociology. From authors like the French philosopher Jacques Derrida, with his theory of the dialectic of opposites, in which he discusses the deconstruction of concepts; Jean Baudrillard, a sociologist who studies the impacts of communication and media in contemporary society and culture; and Herbert Marcuse, German philosopher and sociologist, belonging to the Frankfurt School, which is concerned with the uncontrolled development of technology and rationalism dominant in modern societies. The essay ends with reflections on the difficulty of educating a child in the midst of all the problems discussed by contemporary authors.
\end{abstract}

Keywords: Deconstruction; Education; Contemporary.

[...] A diferença entre um nômade e um colono não é a diferença; o motivo pelo qual o colono teme o nômade não é tanto porque este pode destruir a sua casa, sua vida, mas porque o nômade compromete a sua ideia de horizonte $[. ..] .{ }^{(1)}$

O ser humano está rachado. Nem quebrado nem são, mas simplesmente fendido. Fendido em suas convicções e certezas, por isso angustiado. Fendido em suas produções e ações, por isso perdido. Trincado em sua autoimagem, por isso míope para perceber-se e apreender/compreender o que está sendo providenciado no mundo que o cerca. O que era regra já não é alicerce para o seu fazer. E viva a era da "relatividade"! Não tendo regras (ou relativizando-as), se ilude nas incertezas da "falta de lei", onde a norma passa a ser a criatividade imposta.

Este se desconstrói enquanto ser e constrói a identidade de um novo (velho?) homem. Um homem hiante, confuso, que olha para traz e tem a certeza que não pode recuar ou mesmo 
parar. Um pouco até análogo ao homem barroco, todavia guardando sua peculiaridade de não estar partido totalmente, mas apenas rachado, ferido em sua autoconfiança e fidúcia sobre a ciência, sobre a arte, a religião, sobre a vida social e subjetiva, nas quais apoiou toda a sua esperança de um mundo melhor.

Esse é o homem indefinido dos tempos "pós-modernos", que não é ainda - pelo próprio processo de indeterminação histórica, por essa lacuna processada na incapacidade de prever o seu próprio futuro, no desespero de ser o que há de vir, sem ao menos o saber. Se não é sabedor do seu agir no presente (posto que o passado já não o represente mais e o futuro é uma grande interrogação), se lhe falta a regra, a indicação dos caminhos ao menos, conseqüentemente, se processa uma falsa sensação de liberdade que o ilude na medida em que também o aliena.

Não saber agir, contribui para a formação de suas inseguranças e incompetências diante da vida e diante de si mesmo, desencadeando inúmeros conflitos psíquicos, a desconstrução do sujeito (assim como da idéia que se tem sobre ele), de sua autoimagem e, concomitantemente, o caos social que verificamos em nossos dias. A desconstrução do sujeito desestrutura a própria vida e a própria morte. Vivencia-se o luto do ser humano.

É de pertinente verificação que se avançou tecnologicamente em progressão geométrica, todavia caminhou-se a passos acanhados nas questões voltadas às relações humanas, comportamento e subjetividade. Parece que, nos últimos tempos, tudo isso tem sido autorizado por esses discursos de análise e desconstituição do que estava como certo para a modernidade. Mas quem está preocupado com o que não está escancarado, às vistas? Quem se preocupa com o sofrimento?

O sofrimento humano é privado e, por isso, rechaçado e convocado a comprimir-se numa implosão imposta pelos mandos de uma ciência igualmente fendida entre dois discursos antagônicos. Adversos apenas na sua aparência, porém embevecidos de vaidade, muitas vezes, reforçada pelas academias, que os constroem e aprovam. De um lado, o discurso encruado da reverência à aplicação da majestade senhora da verdade positiva, encharcada de regras cegas, responsáveis por restringir, reduzir e vigiar o pensamento científico. E, do outro, a falácia da desconstrução da norma que corrói e impõe à força a liberdade e criatividade humana. Ambos, em seus discursos beatos, parecem trabalhar em detrimento do ser humano. E para quem a ciência deveria servir mesmo? Palmas a ciência e sua deteriorização!

A que custo social e individual se destroem os modelos, as possibilidades de caminhos? A ciência lê e interpreta a sociedade ou a reinventa em seus discursos? São apenas 
discursos que, mal interpretados ou politicamente bem arquitetados, podem roubar a experiência de muita produção, invalidar (se isso for possível) o próprio processo histórico que nos permite questioná-lo e transformá-lo, por ter percorrido exatamente o caminho que sabemos. Numa negação contundente, porém não dialética, os discursos se desequilibram.

Não se defende aqui a imposição de regras e modelos, a necessidade pura de normas e leis. Não se procura julgar culpados também os discursos "desconstrutivos" e "desestruturantes" das verdades que os antecedem. Há verdades em suas verdades, alguns mais fatalistas outros menos, contudo não basta negar por negar, desconstruir por "desconstruir", "des-significar" sem "re-significar", sem apresentar possibilidades. Como se verifica em $\operatorname{Derrida}^{(2)}$ pretendendo a desconstrução, o que pode sugerir uma destruição, porém tratando-se de encorajar a pluralidade de discursos, legitima a não existência de uma única verdade ou interpretação, com um caráter de disseminação de possíveis e novas verdades contanto que não percamos o sujeito.

Não se pode negar ao homem as possibilidades de conhecer outras perspectivas, apenas expondo um quadro pessimista da vida e do próprio sujeito em suas relações. $\mathrm{O}$ poder/saber científico continua em cheque. Prender e controlar, "vigiar e punir"(3) numa força alienante às normas, já demonstrou que não parece ser o caminho mais confiável para a construção do saber e do sujeito, porém é igualmente perverso desfazer sem propor horizontes. Portanto, onde fica o sujeito diante desses dois discursos? As verdades dizem $o$ que fazer, mas não como. Porque o como é de caráter analítico mais profundo e requer rever e amparar o sujeito, sua história pessoal, grupal, cultural e filogenética, ou seja, ampliar o olhar do exterior para também enxergar a riqueza de dentro.

O discurso da contemporaneidade declara a falência de todas as concepções da modernidade, principalmente: a liberal, a determinista, cartesiana e a marxista. Portanto, fazem alusão a idéias inéditas para tempos inéditos, porém não parecem se dar conta que as contradições do modernismo ainda não foram superadas e, portanto, as versões da pósmodernidade são idéias que apenas receberam uma roupagem atualizada e mais complexa. São concepções que buscam negar a objetividade da modernidade ou sugerem um sujeito volátil e apagado. O que se defende aqui é a preservação do sujeito, combatendo-se a descaracterização e o desaparecimento deste enquanto objeto de estudo. Caberá as ciências humanas estudar apenas os signos e imagens, como alguns autores propõem? Baudrillard, por exemplo: 
No início o signo era a representação de uma realidade básica; depois o signos se mascara e perverte a realidade básica; no terceiro estágio, o signo mascara a ausência de uma realidade básica; no quarto, o atual, o signo não tem qualquer relação com alguma realidade. ${ }^{(4)}$

Não se pode perder de vista que se trata do sujeito historicamente construído através da observação por via de lentes que potencializam o setor econômico como principal instrumento de leitura e interpretação de mundo, mundo este capitalista. O sujeito moderno é facilmente interpretado como atrelado ao advento e desenvolvimento do capitalismo industrial. Já o sujeito "pós-moderno" se perde entre os discursos, pois está no meio de uma transição, atrelado e dependente ao desenvolvimento tecnológico, dos símbolos e imagens sociais. Embora o poder que o símbolo exerce sobre o ser humano existe desde o advento da sociedade pensante, racionalista. Nada de novidade nisto.

O sujeito moderno esteve envolto pelo ideário individualista, da autonomia e racionalismo capitalista, crendo no progresso planejado e futuro previsível para a humanidade. Quando esses objetivos não foram alcançados, o sujeito se frustrou e desacreditou de tudo, surgindo então todas as incertezas e angústias que perturbam a percepção de si e dos outros, assim como das dicotomias tidas como verdadeiras: individual/coletivo, público/privado, ser/ter, real/virtual, bom/mal etc. Exatamente o que Derrida, pretende desconstruir em suas teses a dualidade das verdades absolutas.

Entretanto é desse emaranhado de contingências que nasce o homem "pós-moderno". Este é levado a lidar com as idéias defendidas pela modernidade, ainda não superadas, misturadas a um saudosismo piegas ou desconstrução impiedosa que contribui fortemente para a negação do aqui-agora. Eis o ápice da aflição humana. Isso torna incapaz a possibilidade de dar sentido ao caminho que estamos percorrendo, gerando problemas e sofrimentos profundos para o indivíduo, ainda não solucionáveis nem pela psicologia nem pela pedagogia. Estes expressos de forma camuflada em novas psicopatologias: uma explosão de pessoas depressivas, anoréticas nervosas, síndrome do pânico, ansiedade, estresse, dentre outras.

Verifica-se que o capitalismo tecnológico trouxe um desequilíbrio entre o desejo e a necessidade, estando separados por um abismo a cada hora mais fundo e largo. Segundo Baudrillard, ${ }^{(4)}$ a mídia e tecnologia passam a ser os maiores instrumentos de controle social, cerceando, portanto, os desejos dos sujeitos. A mídia passa a exercer o "poder-saber" denunciado por Foucault sobre a ciência - cada vez mais sutilmente autoritário sobre o 
indivíduo, ditando as maneiras de se relacionar e viver. Portanto, a mídia cria uma realidade virtual, que o mesmo autor classifica de hiper-realidade, a qual substitui a própria realidade, havendo a neutralização das perspectivas de transformação social e a banalização da vida.

A sociedade contemporânea esta marcada pelas necessidades criadas e saciadas economicamente e os desejos não pertencem a si, deseja-se a "criação", o que o outro tem, a imagem inventada para capturar, atrair. Aspira-se os signos e símbolos, as marcas, anseia-se por "ter" suprimindo o "ser". De maneira mais "descartável" ainda, criou-se o fast-food, a geração é globalizadamente $M c$ Donald's, os relacionamos virtuais, etc. Mecanismos criados para domar e tapear o inconformismo com o trabalho duro (que mantém o ciclo acontecendo), dispostos a diminuir as frustrações e tornar a vida mais dinâmica e "divertida". ${ }^{(5)}$ O que vale é a quantidade. Tem-se a leve impressão que este livro já foi lido... Admirável mundo novo! ${ }^{(6)}$

É aí que a fenda se abre e racha a mente do homem... Pois embora planeje e busque esse mundo semiótico, cada vez mais, o ser humano ainda pauta sua formação em modelos modernos para indicar os padrões de vida, família e estar no mundo. Incongruências de um momento de transição social. Em meio a todo o dilema econômico-social demonstrado acima, deparamo-nos com seus reflexos na rees/desestruturação da família, com um reflexo intenso na educação e comportamento das crianças e jovens.

Se o sujeito está rachado, a família, composta por sujeitos, representará essa fissura social. A família pós-moderna não corresponde ao modelo anterior composto por pai-mãefilhos, da sociedade moderna. Novas formas de estruturas familiares surgiram, dentre elas: mãe como esteio financeiro, famílias de casais que foram casados anteriormente, famílias de casais gays, pai e mãe casados pela segunda ou terceira vez, etc. Saindo do ideal ideológico fornecido pelo modo de vida da família moderna, desconstruiu-se a imagem idealizada, mas não se construiu outra. Os membros da família buscam dentro de casa a tipologia familiar de outra época e porque não a localizam, padecem psiquicamente. Sofremos porque não temos ou somos o que gostaríamos de ter ou ser em nosso mundo simbólico, construído através dos diversos fios que estabelecem o tecido cultural do qual nos formamos. Estruturando-se em torno do trabalho e moldando-se totalmente a esse ideal, a família contemporânea exacerba esse traço moderno e sofre.

Para uma família "ter" o que se deseja, precisa trabalhar longas jornadas. Tal valor, trazido pela Família Real européia para o Brasil no século XIX, perpetua-se fortalecida pelo capitalismo, encarcerando cada vez mais os sujeitos ao trabalho como forma de conquista de felicidade e dignidade. Freud chamaria isso de "vantagens mentais" no texto: O futuro de uma 
ilusão. Com as mudanças sociais e econômicas, a mulher passou a trabalhar fora, à medida em que a família sacrifica a educação dos filhos. ${ }^{(7)}$

Atualmente, a maioria das crianças é educada apenas pela escola, avós e/ou babás. Os pais acabam não exercendo controle sobre os filhos, que "se criam". As relações se tornam superficiais e a escola conhece mais as características da criança do que os próprios pais ou representantes legais. No modelo anterior de família, com seus papéis bem definidos se tinha controle, ordem, mas, ao mesmo tempo, revolta, insurgências, traumas. No modelo atual, vêse uma liberdade forçada para as crianças, que crescem "sem limites" (tema de tantas discussões em educação) e, conseqüentemente, têm-se pessoas sem noção do outro, sem preocupação com o coletivo, alheios ao sistema e extremamente inseguros diante da vida e de si mesmos, pois não sabem como devem se comportar. E é esse o retrato do sujeito contemporâneo. A sociedade exige padrões comportamentais, valores são estabelecidos quanto ao passado, mas o invólucro é imposto pela mídia, pelo consumo. O que se verifica é que não existe "receita".

Os pais ultimamente não têm tempo para educar, não lhes sobra ocasião para serem modelos de conduta, então a televisão e o computador (mais novo membro da família) acabam fazendo o papel parental. A "babá” não tem autonomia para educar as crianças, e os avós estão cansados para ser tão severos quanto foram com os pais. Os pais, por sua vez, chegam à noite enfadados e o pouco tempo que têm com os seus filhos, desejam tranqüilidade e harmonia. O que menos desejam é ter que, neste momento de descanso, apresentarem-se rígidos e agressivos. Tornam-se, portanto, financiadores exclusivamente. O tempo que têm livre, os pais "perdem" seus filhos para os entretenimentos.

Aufere-se a escola, deste modo, novo status: a responsabilidade de educar e, caso não faça a contento de tamanha clientela exigente e heterogênea, é ameaçada. Exige-se atualmente da instituição escolar detalhes e exclusividades que não faziam parte de seu papel até bem pouco tempo. Portanto, terceiriza-se a educação, outorgando a escola a imposição de limites, porém sem exageros. A escola é parceira, mas ao mesmo tempo vilã. Verifica-se tal afirmação pelos inúmeros processos jurídicos contra a escola que verificamos em nossos dias. Parabéns a importância dada ao vocábulo "constrangimento"!

Existe também a demanda terapêutica atual dos pais (na sua maioria classe média quem pode bancar tal luxo): o grande sentimento de culpa. Sentem-se culpados por não poder dar atenção a seus filhos, por terem que escolher entre acompanhá-los ou dar-lhes uma "vida melhor", e em nome dessa, mesmo trabalhando demasiado, não conseguem comprar todos as 
novas necessidades criadas pela mídia. Portanto, sentem-se novamente culpados e por isso não podem "cobrar" tanto de seus filhos, já que não cumprem o papel que seria seu. Acumulando culpa, ou, mecanicamente, se tornam produtivos ou sofrem e desesperam. Fico imaginando, qual o lugar da criança neste mundo contemporâneo? O que diria Arriés? ${ }^{(8)} \mathrm{E}$ ainda ficamos pasmados com o aparecimento de "pequenos tiranos". A criança torna-se déspota, sem ao menos poder optar por outra condição. Ela tem sido soberana, pois os "outros" constantemente estão devendo algo. E nesse momento, resiste-se a falta, a frustração, tão importante para a formação do sujeito.

Destarte, os papéis não precisam ser fixos e rígidos, mas precisam ser discutidos e repensados. Não ter modelos, alguma norma ou espelhos tem sido gerador de sofrimento psíquico. E é isso que tem sido o ponto alto de toda essa discussão. Continuamos sendo formados enquanto sujeitos na relação social, através das normas constitui-se os limites de convivência e a noção do outro. A pergunta da existência humana continua: para onde vamos? Se quisermos um mundo mais humano e com olhos na coletividade, precisamos mudar nossos discursos e sistemas formadores de opinião e conduta, educação, mídia, etc.

Quando desconstruímos o sujeito, destruímos a experiência educativa e coletiva de nós mesmos. Se não sabemos quem é esse sujeito atual, como poderemos especular sobre o futuro e, principalmente, sobre o agora? Talvez o próximo passo seja a "re-descoberta" do sujeito. Não há fórmula, mas é na dialética do fazer que construímos nosso pensar e ser. É na atividade humana que criamos consciência de nós mesmos. Ainda olhamos o "estrangeiro", o novo ou, simplesmente, o nômade como uma ameaça, à formação de colonos que temos. $\mathrm{O}$ sujeito que esta nascendo, pós-estruturalista, exige que pensemos sobre algo que ainda não concebemos e isso nos ameaça, diante dessa "chantagem” explicitada. O caminho mais fácil é crer que sucumbiremos, do que permitir que os horizontes do nômade nos invadam.

\section{REFERÊNCIAS}

${ }^{1}$ Bronsky J. Epígrafe. In: Sanches Neto M. Pisador de horizontes. São Paulo: Ed. UEPG; 2006.

${ }^{2}$ Nascimento E. Jacques Derrida: pensar a desconstrução. São Paulo: Ed. Estação Liberdade; 2005.

${ }^{3}$ Foucault M. Vigiar e punir. 16 a ed. Petrópolis, RJ: Vozes; 1997.

${ }^{4}$ Baudrillard J. A sociedade de consumo. Lisboa: Elfos 70 Edições; 2003. 
${ }^{5}$ Marcuse H. Novas formas de controle. In: Ideologia da sociedade industrial. Rio de Janeiro: Zahar; 1967.

${ }^{6}$ Huxley A. Admirável Mundo Novo. São Paulo: Globo; 2000.

${ }^{7}$ Gonçalves HS., Brandao EP. Psicologia jurídica no Brasil. Rio de Janeiro: NAU; 2004.

${ }^{8}$ Arriés P. História social da infância e da família. Rio de Janeiro: LCT; 1978. 